\title{
Impact of the COVID-19 Pandemic on Ophthalmology Residency Training in Portugal
}

\author{
O Impacto da Pandemia COVID-19 no Internato de \\ Formação Específica de Oftalmologia em Portugal
}

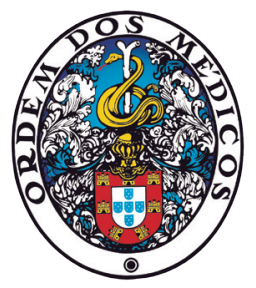

Nisa SILVA ${ }^{1}$, Rita LAIGINHAS ${ }^{2}$, Angelina MEIRELES ${ }^{1,3}$, João BARBOSA BREDA ${ }^{4,5,6}$

Acta Med Port 2020 Oct;33(10):640-648 - https://doi.org/10.20344/amp.14341

\section{ABSTRACT}

Introduction: The purpose of this study was to provide objective and real-life data concerning the impact of the COVID-19 pandemic on ophthalmology residency training in Portugal.

Material and Methods: Descriptive survey-based study applied to current Portuguese ophthalmology residents ( $n=80$ eligible).

Results: Seventy-five residents participated (94\% response rate). All except one (99\%) admitted a change in their routine clinical practice during the pandemic, and most $(89 \%)$ continued to be engaged in ophthalmology department duties. Twenty-five percent were deployed to COVID-19 units, which was combined with ophthalmological activities in about half of them (47\%). A significant proportion of participants stated that they were enrolled in the following ophthalmological activities: emergency/inpatient care (87\%), outpatient visits (73\%; general $70 \%$ vs subspecialty $29 \%$ ), and surgical procedures (64\%). Twenty-five percent did not assist in any outpatient visits and $36 \%$ did not participate in any surgical procedures. On a scale from 1 (no impact) to 5 (maximum impact), most participants classified their perceived negative impact of the pandemic on the training program as $3(24 \%), 4(40 \%)$, or $5(27 \%)$. Participants highly agreed with the extension of the residency program $(80 \%)$ in order to to make up for training disruption.

Discussion: Most trainees provided ophthalmological care during the pandemic. However, those clinical activities were essentially related to general and emergency care. Surgical experience was significantly curtailed. As such, strategies are needed to guarantee a high-quality learning process. Further studies are required to develop an international perspective on how ophthalmology training programs have been affected so that educational organizations can make recommendations regarding standardized adjustments to training programs.

Conclusion: The COVID-19 pandemic has significantly impacted the training of ophthalmology residents nationwide.

Keywords: Coronavirus Infections; COVID-19; Internship and Residency; Ophthalmology; Pandemics; Portugal

\section{RESUMO}

Introdução: Este estudo teve como objetivo avaliar o impacto da pandemia COVID-19 no internato de Formação Específica de Oftalmologia em Portugal.

Material e Métodos: Estudo descritivo dos resultados obtidos de um questionário aplicado a todos os internos de Formação Específica de Oftalmologia em Portugal $(n=80)$.

Resultados: Setenta e cinco internos participaram no estudo (taxa de resposta de $94 \%$ ). Excetuando um caso, todos (99\%) admitiram alteração da sua prática clínica durante a pandemia, e a maioria (89\%) manteve atividades clínicas no seu serviço de Oftalmologia. Vinte e cinco porcento foram integrados em unidades COVID-19, e metade desses inquiridos (47\%) desempenharam concomitantemente atividades no âmbito da oftalmologia. Uma percentagem significativa dos inquiridos referiu estar envolvido nas seguintes atividades clínicas oftalmológicas: serviço de Urgência/consultas internas (87\%), consultas externas (73\%: geral $70 \%$ vs subespecialidade $29 \%$ ), e cirurgias (64\%). Vinte e cinco porcento não participaram em consultas externas, e $36 \%$ em procedimentos cirúrgicos. Numa escala de 1 (sem impacto) a 5 (máximo impacto), a maioria dos inquiridos classificou o impacto percecionado da pandemia no internato de Formação Específica de Oftalmologia em 3 (34\%), 4 (40\%) e 5 (27\%). Oitenta porcento dos inquiridos enumerou a extensão do período do internato de Formação Específica como uma medida a adotar para minimizar o impacto negativo da pandemia.

Discussão: A maioria dos internos mantiveram-se a desempenhar atividades clínicas no seu serviço de Oftalmologia, principalmente no âmbito da oftalmologia geral e de urgência. O desempenho de atividade cirúrgica foi largamente afetado. São necessárias estratégias adaptativas para garantir a continuação adequada da formação dos internos. Futuros estudos noutros contextos geográficos permitirão perceber de que forma os programas de formação em oftalmologia estão a ser afetados ao nível internacional, para que as organizações educacionais possam elaborar recomendações.

Conclusão: A pandemia COVID-19 teve um impacto significativo no internato de Formação Específica de Oftalmologia em Portugal. Palavras-chave: COVID-19; Infecções por Coronavírus; Internato e Residência; Oftalmologia; Pandemia; Portugal

\section{INTRODUCTION}

The novel coronavirus, meanwhile named severe acute respiratory syndrome coronavirus 2 (SARS-CoV-2), was first identified in China. ${ }^{1}$ The infection spread rapidly world-

wide which led the World Health Organization to declare a "public health emergency" by January $30^{\text {th }} 2020^{2}$ and afterwards a pandemic on March $11^{\text {th }} 2020 .^{3}$ In Portugal, the

1. Department of Ophthalmology. Centro Hospitalar Universitário do Porto. Porto. Portugal.

2. Department of Ophthalmology. Centro Hospitalar de Entre o Douro e Vouga. Santa Maria da Feira. Portugal.

3. Instituto de Ciências Biomédicas Abel Salazar. Universidade do Porto. Porto. Portugal.

4. Cardiovascular R\&D Center. Faculty of Medicine. Universidade do Porto. Porto. Portugal.

5. Department of Ophthalmology. Centro Hospitalar e Universitário São João. Porto. Portugal.

6. Research Group Ophthalmology. Department of Neurosciences. Katholieke Universiteit Leuven. Leuven. Belgium.

$\triangle$ Autor correspondente: Nisa Silva. nisapinhosilva@gmail.com

Recebido: 14 de junho de 2020 - Aceite: 24 de agosto de 2020 | Copyright @ Ordem dos Médicos 2020 
"state of emergency" was announced on March $18^{\text {th }} 2020$ and lasted until May $2^{\text {nd }}$, with people placed under voluntary lockdown all over the country. ${ }^{4,5}$

In an attempt to mitigate the spread of the virus, healthcare systems had to rapidly reshape their framework considering that a substantial number of patients could be infected in healthcare settings. ${ }^{6,7}$ Addressing this challenge caused a shift from patient-centered medicine to a community-centered approach and all medical fields faced the challenge of reviewing their prioritization strategies regarding both outpatient services and surgical procedures. In the particular case of ophthalmology, there were concerning reports suggesting that ophthalmologists could be at higher risk of infection due to the proximity to patients during clinical assessment. ${ }^{8}$ In response, several organizations, including the American Academy of Ophthalmology, promptly recommended in-person examinations only for those requiring urgent or emergent care, with elective activity being consequently postponed or carried out via telemedicine. ${ }^{9}$ Ophthalmology registered the highest estimated decline in outpatient visits (approximately 79\%) among all medical fields. ${ }^{10}$ Elective surgical procedures were also postponed, with the activity being primarily restricted to urgent or emergent conditions. ${ }^{9}$

Overall, this reorganization and considerable reduction in clinical activities represented an unprecedented challenge for ophthalmology residency training programs and there are concerns that it might impact the course of training for the current resident cohort. Many departments temporarily changed their residency programs, suspending normal clinical rotation schedules and overhauling residents into alternating coverage teams in order to reduce the risk of cross-contamination. Moreover, the additional spare time seems to have been used heterogeneously; while some residents were able to expand their scientific curriculum, others have been called to the front line to care for patients with COVID-19 (the designation of the disease caused by SARS-CoV-2). ${ }^{11}$

It is thus essential to objectively monitor the impact of the pandemic in residency programs and ensure the implementation of alternative strategies to cope with this shortcoming.

This survey-based study aimed to provide an overview of the impact of the COVID-19 pandemic on ophthalmology training in Portugal.

\section{MATERIAL AND METHODS}

This is a nationwide cross-sectional study. An anonymous, web-based survey (see Appendix 1: https://www. actamedicaportuguesa.com/revista/index.php/amp/article/ view/14341/Appendix_01.pdf) was developed by all authors, which includes residents and attending ophthalmologists, from a variety of ophthalmology departments. The survey was approved by the Portuguese College of Ophthalmology and the Portuguese Group of Young Ophthalmologists. A pilot study was tested in a small sample of Portuguese residents $(n=8)$ in order to validate the content, clarity of the questions, and time necessary to complete the survey. All Portuguese ophthalmology residents $(n=80)^{12}$ received the survey on April $23^{\text {rd }} 2020$ via email, and replies were collected by April $25^{\text {th }} 2020$ (one week before the 'state of emergency' was lifted). Therefore, the questionnaire evaluated the period between the March $11^{\text {th }}$ and Apri $23^{\text {rd }}$ (since the survey was sent in the latter). Willingness to participate in the study was voluntary and consent was given to use the aggregated data resulting from the survey. Since the data was completely anonymous, no personal information was collected, and participants were informed how the data would be handled providing informed consent before answering the questionnaire, ethical approval was not deemed necessary.

The survey consisted of 28 questions (25 multiple choice and three open response), grouped into four sections. The first section included demographics and training setting. The second section focused on the activities taking place at the ophthalmology department during the pandemic. The third section centered on the activities performed by the resident, ranging from outpatient visits, surgical procedures, clinical research and online education. The fourth section comprised questions about the personal perspective and concerns of the residents. Finally, a free text question allowed residents to suggest additional measures that could be adopted so as to mitigate the impact of the pandemic in their residency program.

\section{Statistical analysis}

Categorical variables were described through absolute and relative frequencies and compared using Fisher's test or the chi-square test, as appropriate. Continuous variables were described as means and standard deviations for variables with a normal distribution or medians and ranges for variables with a skewed distribution. The normality of the distributions was checked using the Shapiro-Wilk test. Student's $t$-test was used to compare continuous variables with normal distribution, while the Mann-Whitney test was used to compare continuous variables with non-normal distribution. Differences among residents from different years were evaluated with the use of an analysis of variance (ANOVA) test. Descriptive analysis was performed using SPSS version 24 (IBM SPSS Statistics for Windows, Version 24.0. Armonk, NY, USA).

\section{RESULTS}

The survey was completed by 75 residents $(94 \%$ response rate). All responses were obtained within 48 hours after the questionnaire was made available. Results by section are detailed bellow.

\section{Section 1: Demographics and training setting}

Fifty-nine percent $(n=44)$ of the respondents were female, with a median age of 27 years (range $24-38$ ). Regarding the year of residency, $25 \%(n=19)$ were in the first year, $21 \%(n=16)$ in the second year, $27 \%(n=20)$ in the third year and $27 \%(n=20)$ in the fourth (last) year. 
Nearly all of the respondents $(97 \%, \mathrm{n}=73)$ were trainees in a hospital assigned to treat patients infected with SARSCoV-2.

Most of the participating residents $(89 \%, n=67)$ continued to work in their ophthalmology department during the pandemic. Twenty-five percent $(n=19)$ had been integrated into medical teams in COVID-19 units, and about half of those $(47 \%, n=9)$ were working concomitantly in the ophthalmology department.

\section{Section 2: Clinical practice of ophthalmology depart- ments during the COVID-19 pandemic}

Table 1 details the responses regarding clinical practice during the pandemic in the ophthalmology departments surveyed. All the respondents answered that clinical practice changed in their ophthalmology department since the beginning of the pandemic. The main in-person clinical activities performed during the pandemic were emergency/inpatient care $(100 \%, \mathrm{n}=75)$, priority subspecialty outpatient visits $(88 \%, n=66)$, priority surgeries $(79 \%, n=59)$ and priority general outpatient visits $(73 \%, n=55)$. No department performed elective ophthalmology surgeries.

\section{Section 3: Ophthalmology training during the COVID-19 pandemic}

Table 2 details the responses regarding ophthalmology training during the COVID-19 pandemic. The clinical practice of nearly all participants $(99 \%, n=74)$ changed since the beginning of the pandemic. A significant proportion of participants mentioned that they were engaged in the following activities within the ophthalmology departments: emergency/inpatient care $(87 \%, n=65)$, outpatient visits $(73 \%, n=55)$ and surgical procedures $(64 \%, n=48)$.

Regarding outpatient clinics, $63 \%(n=47)$ performed telemedicine visits, $52 \%(n=39)$ performed in-person visits, $41 \%(n=31)$ participated in both and 25\% $(n=20)$ did not assist in any outpatient visits. Specific rates for the type of visit, general or subspecialty, are presented in Table 2. A higher proportion of respondents were engaged in general ophthalmology clinics $(70 \%, n=53)$ compared with subspecialty clinics $(29 \%, n=22)$.

The number of visits and surgical procedures performed is outlined in Table 2. During the pandemic, residents participated in the following surgical activities: intravitreal injections $(52 \%, n=39)$, emergency surgery $(49 \%, n=37)$, retinal surgery $(21 \%, n=16)$, glaucoma surgery $(19 \%, n=$ $14)$ and cataract surgery $(1 \%, n=1)$. If we exclude intravitreal injections, $49 \%(n=37)$ of the residents did not assist in any surgical procedures. In addition, whereas only $8 \%$ (n =69) reported not participating in cataract surgeries before the pandemic, during the pandemic this rate increased to $99 \%(n=74)$.

Clinical research was conducted by $43 \%(n=32)$ of the respondents during the pandemic. Forty-two percent ( $n=32$ ) admitted an increase in the number of submitted papers, and $39 \%(n=29)$ mentioned an increase in the number of submitted abstracts to congresses. Most of the respondents $(80 \%, n=60)$ declared having had more time to develop research projects. Eighty-nine percent $(n=67)$ attended virtual meetings.

\section{Section 4: Subjective perspective on the impact of the COVID-19 pandemic on the overall training program}

Table 3 summarizes the responses regarding personal perspective concerning the impact of the COVID-19 pandemic on the training program. The perceived impact of the pandemic was rated by the participants from 1 (no impact) to 5 (maximum impact) as shown in Fig. 1: 1 was reported by $1 \%(n=1), 2$ by $8 \%(n=6), 3$ by $24 \%(n=18), 4$ by $40 \%$ $(n=30)$ and 5 by $27 \%(n=20)$. There were no statistically significant differences between the median rate from residents deployed and not deployed to COVID-19 units (4.5 vs $4.0, p=0.10)$. As strategies to offset the negative impact of the pandemic, participants agreed with the extension of the

Table 1 - Clinical practice of ophthalmology departments during the COVID-19 pandemic

\begin{tabular}{|c|c|c|}
\hline & & Total $(n=75)$ \\
\hline Change in clinical practice, $\mathrm{n}(\%)$ & & $75(100)$ \\
\hline \multicolumn{3}{|l|}{ Clinical activities (in-person), $n(\%)^{*}$} \\
\hline Emergency room/inpatient visits & & $75(100)$ \\
\hline \multirow[t]{4}{*}{ Outpatient visits } & Priority general & $55(73)$ \\
\hline & Elective general & $2(2)$ \\
\hline & Priority subspecialty & $66(88)$ \\
\hline & Elective subspecialty & $1(1)$ \\
\hline \multirow{2}{*}{ Surgeries } & Priority (not emergency-related) & $59(79)$ \\
\hline & Elective & $0(0)$ \\
\hline \multicolumn{3}{|c|}{ Following guidelines in clinical practice, $\mathrm{n}(\%)$} \\
\hline & No & $5(7)$ \\
\hline & Internal guidelines & $52(69)$ \\
\hline & Guidelines from national societies & $9(12)$ \\
\hline & Guidelines from international societies & $9(12)$ \\
\hline
\end{tabular}


Table 2 - Ophthalmology training during the COVID-19 pandemic

\begin{tabular}{|c|c|c|}
\hline & & Total $(\mathbf{n}=7$ \\
\hline Change in clinical practice, $n(\%)$ & & $74(99)$ \\
\hline \multicolumn{3}{|l|}{ Work hours, n (\%) } \\
\hline & Increased & $1(1)$ \\
\hline & Decreased & $68(91)$ \\
\hline & Not changed & $6(8)$ \\
\hline \multicolumn{3}{|l|}{ Clinical activities, $n(\%)^{*}$} \\
\hline & Emergency room/inpatient visits & $65(87)$ \\
\hline & Outpatient visits & $55(73)$ \\
\hline & Telemedicine & $47(63)$ \\
\hline & Laser procedures & $12(16)$ \\
\hline & Surgical procedures & $48(64)$ \\
\hline & Clinical research & $32(43)$ \\
\hline & Administrative duties & $36(48)$ \\
\hline & None & $8(11)$ \\
\hline Remote access to work from home, $n(\%)$ & & $30(40)$ \\
\hline \multicolumn{3}{|l|}{ Outpatient clinic, $n(\%)^{*}$} \\
\hline & General telemedicine visits & $45(60)$ \\
\hline & General face-to-face visits & $31(41)$ \\
\hline & Subspecialty telemedicine visits & $16(21)$ \\
\hline & Subspecialty face-to-face visits & $19(25)$ \\
\hline & None & $20(27)$ \\
\hline
\end{tabular}

Number of visits, $n(\%)$

Face-to-face visits

$$
\begin{array}{r}
\text { None } \\
1-10 \\
11-20 \\
21-30 \\
>30
\end{array}
$$

Surgical procedures, $\mathrm{n}(\%)^{*}$

$36(48)$
$25(33)$
$7(9)$
$2(3)$
$5(7)$

36 (48)
Telemedicine visits

28 (37)

$11(15)$

8 (11)

\begin{tabular}{rc} 
Cataract surgery & $1(1)$ \\
Refractive surgery & $0(0)$ \\
Corneal surgery & $0(0)$ \\
Retinal surgery & $16(21)$ \\
Strabismus surgery & $0(0)$ \\
Glaucoma surgery & $14(19)$ \\
Oculoplastic surgery & $0(0)$ \\
Intravitreal injections & $39(52)$ \\
Emergency surgery & $37(49)$ \\
None & $27(36)$ \\
\hline
\end{tabular}

training program $(80 \%, n=60)$, a curriculum incorporating targeted surgical procedures $(56 \%, n=42)$ and development of virtual platforms for educational courses $(52 \%, \mathrm{n}$ $=39$ ). Future simulation training programs $(44 \%, n=33)$, virtual platforms for congresses and webinars $(41 \%, n=$ $31)$ and virtual platforms with educational surgical videos $(39 \%, n=29)$ were also significantly selected by the par- ticipants. Five free text responses were received regarding additional strategies. Among these, two additional measures were suggested: adapting the end-of-residency exam (which is mandatory in Portugal) to the training limitations experienced during this period, excluding, for instance, presentations in international conferences from the final evaluation parameters; providing subspecialty fellowships 
Table 2 - Ophthalmology training during the COVID-19 pandemic (final section)

Total $(n=75)$

Number of surgeries (excluding intravitreal injections), $\mathrm{n}(\%)$

Before COVID-19 pandemic

$\begin{array}{rc}\text { None } & 1(1) \\ 1-5 & 7(9) \\ 6-10 & 22(29) \\ 11-20 & 31(41) \\ >20 & 14(19)\end{array}$

Number of cataract surgeries, $n(\%)$

$\begin{array}{rc} & \text { Before COVID-19 pandemic } \\ \text { None } & 6(8) \\ 1-5 & 17(23) \\ 6-10 & 37(49) \\ 11-20 & 11(15) \\ >20 & 4(5)\end{array}$

Number of submitted papers, $\mathrm{n}(\%)$

\begin{tabular}{|c|c|c|}
\hline & Increased & $32(43)$ \\
\hline & Decreased & $6(8)$ \\
\hline & Not changed & $37(49)$ \\
\hline \multicolumn{3}{|l|}{ Number of submitted abstracts to congresses, $n(\%)$} \\
\hline & Increased & $29(39)$ \\
\hline & Decreased & $6(8)$ \\
\hline & Not changed & $29(39)$ \\
\hline Feeling of having more time to prepare research studies, $\mathrm{n}(\%)$ & & $60(80)$ \\
\hline Virtual meetings attendance, $\mathrm{n}(\%)$ & & $67(89)$ \\
\hline
\end{tabular}

* More than one answer could be selected

across national academic medical centers as an alternative to international exchange (which is the usual choice for most Portuguese residents).

\section{Comparison of results among residency years}

A smaller percentage of ophthalmology junior residents (first- and second-year residents) were performing telemedicine visits $(46 \%$ vs $78 \%, p=0.005)$ and surgical procedures (49\% vs $78 \%, p=0.009$ ) compared with senior residents (third- and fourth-year residents). There were no overall statistically significant differences between the median rate of perceived impact of the pandemic on the training in different residency years (4.0 for each of the four years; $p$ $=0.425$ ).

\section{DISCUSSION}

In this study, we used a survey-based approach to evaluate the impact of the COVID-19 pandemic in Portuguese ophthalmology residency programs since the beginning of the pandemic on March $11^{\text {th }}$ to April $23^{\text {rd }}$ (when the survey was applied). We found that reorganization of clinical practice induced by the COVID-19 pandemic seems to have decreased the number of learning opportunities of residents in the context of the ophthalmology residency, thus demanding revised and novel strategies to counterbalance this
During COVID-19 pandemic

$$
\begin{gathered}
37(49) \\
35(47) \\
1(1) \\
2(3) \\
0(0)
\end{gathered}
$$

During COVID-19 pandemic

74 (99)

1 (1)

$0(0)$

$0(0)$

$0(0)$ breach in the curriculum.

The COVID-19 pandemic is threatening residency training programs across all medical fields, but this most likely happens disproportionately. Some specialties, including internal medicine, infectious diseases and anesthesia, were able to use their acquired skills, and learn new ones, when recruited to manage COVID-19 patients. ${ }^{13,14}$ On the other hand, surgical fields, such as ophthalmology, were highly affected, with daily activities restricted only to those deemed essential. ${ }^{15-17}$ To the best of our knowledge, few publications addressed the impact of the COVID-19 pandemic in ophthalmology residency programs, and from those, only one presents objective data. ${ }^{18-20}$ A nationwide study conducted in India with ophthalmology trainees (96\% of which were enrolled in residency programs; $n=716$, unknown response rate) revealed that $25 \%$ had been deployed to COVID-19 duties and $81 \%$ felt that the COVID-19 lockdown adversely affected their learning. ${ }^{20}$

According to objective data from our study, ophthalmology teaching departments were following the recommendations of public health organizations and scheduling only priority, urgent and emergent visits, and procedures. Routine ambulatory visits and surgeries were largely postponed. These drastic changes have demanded an adjustment in the resident's schedules with $99 \%$ of the survey 
Table 3 - Subjective perspective of the impact of the COVID-19 pandemic in the overall training program

Total $(n=75)$

Perceived impact in training program, $\mathrm{n}(\%)$

Perceived impact in training program, median (range)

Strategies to minimize the negative impact, $n(\%)^{*}$
$1(1)$

$4(1-5)$

$33(44)$

\footnotetext{
* More than one answer could be selected
}

participants reporting changes to their routine clinical practice. A significant proportion of residents did not assist in any outpatient visits (25\%) or surgical procedures (49\%, excluding intravitreal injections). Additionally, $25 \%$ were deployed to work in the front-line response for COVID-19 patients. This reassignment may have represented an opportunity to establish relationships with colleagues of other specialties, enhance medical knowledge, develop abilities of dynamic teamwork, and expand perspectives about health policy and global health. Nevertheless, this training disruption could have raised concerns about accomplishing the residency requirements and affect the well-being of these trainees. The perceived impact of the pandemic in Portuguese ophthalmology residency training programs was not significantly higher among those reassigned to COVID-19 units, which most likely happened because most of them were also working in their ophthalmology department. In fact, most of the respondents (89\%) were engaged in activities of their ophthalmology department, mostly focused in general (priority) and emergency/inpatient care.

Telemedicine has become the primary and safest form of outpatient clinical care in healthcare settings. ${ }^{21}$ We reported a significant rate $(62 \%)$ of residents actively participating in telemedicine clinics. By participating in these

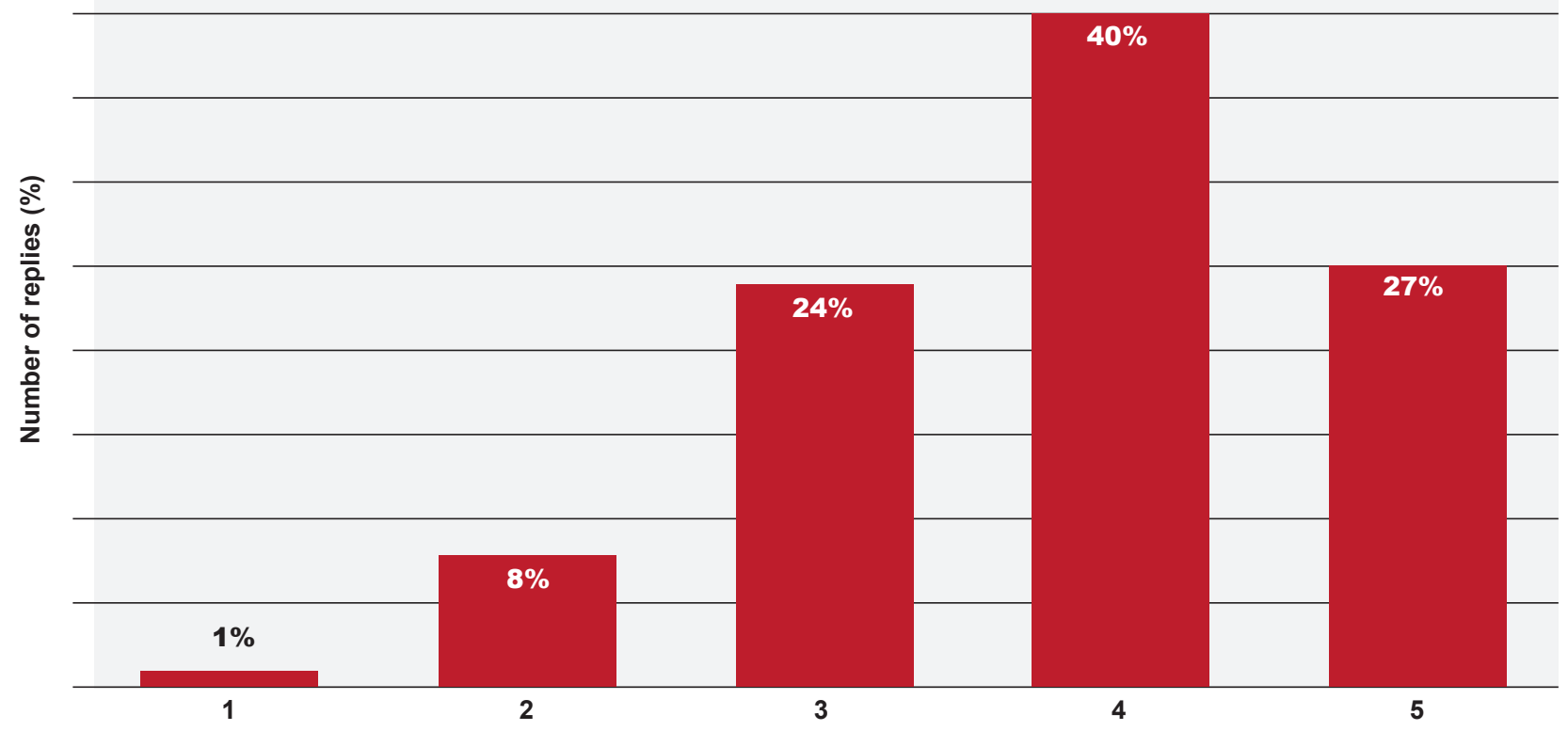

Figure 1 - The perceived impact of the COVID-19 pandemic on residency training programs 
virtual visits, residents can review charts and contribute to patient counseling under the supervision of an attending ophthalmologist. Nonetheless, physicians, especially in fields such as ophthalmology that is highly dependent on technical equipment, can find telemedicine delivery particularly challenging. The need for social distancing may accelerate the movement towards other consultation methods, such as virtual clinics with clinical data acquisition outside the hospital facilities in a shared-care scheme. ${ }^{22}$ This could also be done for screening efforts, such as those regarding diabetic retinopathy, age-related macular degeneration, and glaucoma. ${ }^{23}$ Residents could benefit from a formal incorporation of telemedicine/virtual patient visits into their residency curriculum.

Surgical skills are among the most valuable competencies for ophthalmologists in training. During the pandemic, surgical experience was limited by the reduction in nonessential surgical volume and by the prioritization of experienced faculty to participate in surgical activity. Our survey revealed that nearly half of residents were not participating in any surgical procedures and, in the other half, the number of surgical cases was curtailed. These data raise concerns about the confidence of trainees and their acquisition of technical skills, particularly considering that a reduction in surgical output is expected to continue for some time. It is important to highlight that many ophthalmology residency programs stipulate the minimum number of procedures that residents are expected to have assisted in or performed as primary surgeon, with significant variability across the globe..$^{24,25}$

For some residents, the reduction in clinical responsibilities meant more time to focus on research work. An increase in research productivity was found in $40 \%$ of the residents. Moreover, there was a nationwide attempt to provide physicians with remote access to electronic medical records in order to allow telemedicine to be conducted outside hospital facilities. This has enabled residents to conduct retrospective research work remotely. This is particularly important given the current limitations in conducting clinical trials.

Our survey was built to capture the concerns of current trainees in order to guide decision-making by program directors after the first wave of the pandemic. On a five-point scale, a significant proportion of residents rated the impact of the pandemic in ophthalmology training as 4 (40\%). Junior residents seem to be the most impacted due to their diminished participation in ophthalmology procedures at the initial stage of their learning curve. Nonetheless, the level of impact expressed was similar between all four residency years. Strategies to optimize educational opportunities and offset the abrupt cessation of elective clinical activities require planning. One of such strategies might be extending residency programs in order to regain lost time in training. This strategy reached $80 \%$ of agreement among participants in the survey. The second most consensual strategy (56\% of acceptance) was a future goal-directed surgical curriculum. Moreover, a significant proportion of respondents mentioned the creation of courses (52\%), conferences and webinars (41\%), and surgical videos $(39 \%)$ in virtual platforms directed for trainees. The unique opportunities to embrace didactic and web-based learning as alternatives to traditional educational methods have been largely mentioned in the literature from a variety of medical fields. ${ }^{26,27}$ For ophthalmology residents, e-learning resources have been offered by ophthalmology organizations (e.g. International Council of Ophthalmology), American Academy of Ophthalmology) to promote active independent study. ${ }^{28}$ Furthermore, ophthalmology conferences have started to move to virtual platforms, in order to support scientific presentations and allow research efforts to be disseminated. Other advantages include the ability to revisit digitally recorded sessions, and environmental and financial savings on transportation. Video-based surgical education is another form of web-based learning, which has proved to be effective but can hardly replace the technical skills acquired in the operating room. ${ }^{29}$ Regarding the trend towards web-based learning, a virtual curriculum could be implemented allowing program directors to monitor resident's independent efforts towards proficiency. Another option to enhance surgical education is simulation training, which may serve an important role for surgical specialties in the wake of the COVID-19 pandemic. In ophthalmology, these systems exist throughout the various subspecialties ${ }^{30}$; the most commonly used is the EyeSi virtual reality surgical simulator (VR Magic). ${ }^{31}$ The association between EyeSi virtual reality training and reduced complication rates in live surgery has been demonstrated. ${ }^{32}$ Nonetheless, a lack of standardized incorporation into the residency curricula, low-quality of validation study designs, and costs have been the major barriers to widespread adoption. ${ }^{30-32}$

We are aware that our study has the inherent limitations of survey-based research. First, given the rapid evolution of the pandemic we had no time to validate the questionnaire and different interpretations are possible. Second, it may happen that the perspective of the respondents changes with time, as feelings and emotions are prone to influence the answers during these challenging times. Third, it only represents the reality of one country. Besides the potential limitations, our study has as a major strength the almost total representability of the target population ( $94 \%$ response rate). Besides, this questionnaire was conducted during the peak of the pandemic in Portugal and care was taken to obtain the responses in a short period of time before this state was lifted on May $2^{\text {nd }}$. In addition, this is one of the first studies to provide objective data on the impact of the COVID-19 pandemic in ophthalmology residency training programs.

Similar studies in other countries/regions would provide an international perspective on how ophthalmology training programs have been affected and the different strategies that are being employed to cope with the effects of the COVID-19 pandemic.

\section{CONCLUSION}

The COVID-19 pandemic has significantly impacted the training of ophthalmology residents. While one quarter of 
residents was deployed to COVID-19 units, most ophthalmology trainees still performed clinical activities within ophthalmology departments during the pandemic. As ophthalmology departments adapted, residents were essentially dedicated to emergent/inpatient and priority general care. The lower amount of time spent on subspecialty and surgical electives led to a drastic reduction in learning experiences. This is aggravated by the fact that it is not yet clear when, and if, the output of ophthalmology departments will recover to pre-COVID-19 numbers. A variety of short- and long-term strategies, including extension of the residency program, web-based education, surgical simulation, and curriculum adjustments, need to be considered in order to guarantee high-quality training programs. This pandemic has provided an unprecedented opportunity to offer standardized training in ophthalmology, thus levelling the ophthalmology curriculum.

\section{PROTECTION OF HUMANS AND ANIMALS}

The authors declare that the procedures were followed according to the regulations established by the Clinical Research and Ethics Committee and to the 2013 Helsinki Declaration of the World Medical Association.

\section{DATA CONFIDENTIALITY}

The authors declare having followed the protocols in use at their working center regarding patients' data publication.

\section{COMPETING INTERESTS}

The authors have declared that no competing interests exist.

\section{FUNDING SOURCES}

This research received no specific grant from any funding agency in the public, commercial, or not-for-profit sectors.

15. Porpiglia F, Checcucci E, Amparore D, Verri P, Campi R, Claps F, et al. Slowdown of urology residents' learning curve during the COVID-19 emergency. BJU Int. 2020;10.1111/bju.15076.

16. Clark VE. Editorial. Impact of COVID-19 on neurosurgery resident research training. J Neurosurg. 2020;1-2.

17. Kogan M, Klein SE, Hannon CP, Nolte MT. Orthopaedic education during the COVID-19 pandemic. J Am Acad Orthop Surg. 2020;28:e456-64.

18. Chen RW, Abazari A, Dhar S, Fredrick DR, Friedman IB, Glass LR, et al. Living with COVID-19: a perspective from New York Area Ophthalmology Residency Program Directors at the epicenter of the pandemic. Ophthalmology. 2020; 127:e47-8.

19. Wong TY, Bandello F. Academic Ophthalmology during and after the COVID-19 Pandemic. Ophthalmology. 2020;127:e51-2.

20. Mishra D, Nair AG, Gandhi RA, Gogate P. The impact of COVID-19 related lockdown on ophthalmology training programs in India outcomes of a survey. Indian J Ophthalmol. 2020;68:999-1004.

21. Moazzami B, Razavi-Khorasani N, Dooghaie Moghadam A, Farokhi E, Rezaei N. COVID-19 and telemedicine: Immediate action required for maintaining healthcare providers well-being. J Clin Virol. 2020;126:104345.

22. Jayaram H, Strouthidis NG, Gazzard G. The COVID-19 pandemic will redefine the future delivery of glaucoma care. Eye. 2020;1-3.

23. Rathi S, Tsui E, Mehta N, Zahid S, Schuman JS. The current state of Teleophthalmology in the United States. Ophthalmology. 2017;124:172934.

24. Accreditation Council for Graduate Medical Education. Required Minimum Number of Procedures for Graduating Residents in Ophthalmology - Review Committee for Ophthalmology. 2014 [accessed 2020 May 29]. Available from: https://www.acgme.org/ Portals/0/PFAssets/ProgramResources/240_Oph_Minimum_Numbers. pdf.

25. Portaria n. ${ }^{\circ}$ 550/2004. Diário da República, I Série-B, n. ${ }^{\circ} 119$ (2004/05/21). p.3248-53.

26. Chick RC, Clifton GT, Peace KM, Propper BW, Hale DF, Alseidi AA, et al. Using Technology to Maintain the Education of Residents During the COVID-19 Pandemic. J Surg Educ. 2020;S1931-7204(20)30084-2.

27. Claps F, Amparore D, Esperto F, Giovanni C, Cristian F, Andrea M, et al. Smart learning for urology residents during the COVID-19 pandemic and beyond: insights from a nationwide survey in Italy. Minerva Urol Nefrol. 2020 (in press). doi: 10.23736/S0393-2249.20.03921-1.

28. International Council of Opthtalmology. E-Learning. [accessed 2020 May 29]. 2020. Available from: http://www.icoph.org/refocusing_education/ educational_programs/e_learning.html.

29. Ahmet A, Gamze K, Rustem M, Sezen KA. Is video-based education an effective method in surgical education? A systematic review. J Surg Educ. 2018;75:1150-8.

30. Lee R, Raison N, Lau WY, Aydin A, Dasgupta P, Ahmed K, et al. A 
systematic review of simulation-based training tools for technical and non-technical skills in ophthalmology. Eye. 2020 (in press). doi: 10.1038/ s41433-020-0832-1.

31. Ferris JD, Donachie PH, Johnston RL, Barnes B, Olaitan M, Sparrow JM. Royal College of Ophthalmologists' National Ophthalmology Database study of cataract surgery: report 6. The impact of EyeSi virtual reality training on complications rates of cataract surgery performed by first and second year trainees. Br J Ophthalmol. 2020;104:324-9.

32. Thomsen AS, Subhi Y, Kiilgaard JF, Cour ML, Konge L. Update on simulation-based surgical training and assessment in ophthalmology: a systematic review. Ophthalmology. 2015;122:1111-30.e1. 